\title{
Studying the Impact of Online Homework on the Perceptions, Attitudes, Study Habits, and Learning Experiences of Chemistry Students
}

\author{
Issa I. Salame ${ }^{1^{\star}}$, Enji Hanna ${ }^{1}$
}

${ }^{1}$ The City College of New York of The City University of New York, UNITED STATES

*Corresponding Author: isalame@ccny.cuny.edu

Citation: Salame, I. I., \& Hanna, E. (2020). Studying the impact of online homework on the perceptions, attitudes, study habits, and learning experiences of chemistry students. Interdisciplinary Journal of Environmental and Science Education, 16(4), e2221. https://doi.org/ 10.29333/ijese/8543

\begin{abstract}
ARTICLE INFO
ABSTRACT

Received:

26 May 2020

The importance of providing students with opportunities to solve problems and providing them with

Accepted: feedback on their learning cannot be underscored. Providing individualized feedback to students in large enrollment classes, such as general chemistry, is an impossible task for instructors. Online homework

Accepted: provides a solution to this problem. College faculty have overall been supportive of online homework and learning resources because it reduces the time they spend grading, entering grades, and returning paper-based homework especially that the class sizes have been steadily increasing over the past several years. The purpose of this paper is to study students' perceptions about the usefulness of online homework, the role it plays in improving their problem solving skills and study habits, and the effect it has on their attitudes and learning. Data was collected using a Likert-type and open-ended questionnaire from students enrolled in general chemistry courses. Our data suggests that online homework had a positive impact on students' perceptions, attitudes, learning experiences, understanding, and learning outcomes. It also increased the amount of time on tasks for students which has the benefit of meaningful learning, engagement in the content, and achievement. Finally, our data suggests that online homework contributed to students' improved active engagement in the course, study habits, and understanding.
\end{abstract}

Keywords: chemistry education research, general chemistry, online homework

\section{INTRODUCTION}

Homework at all grade levels has been found to positively impact learning and more so for older students (Cooper, 2001). Instructors of general chemistry courses face difficulties with assigning, collecting and grading homework. This problem has been compounded by the fact that most general chemistry courses have large enrollments well exceeding 200 students per class. Online homework provides a possible solution where students work on problems and are graded and given feedback by the online system. Additionally, online homework has been found to have a positive impact on student learning (Charlesworth \& Vician, 2003). Furthermore, online homework positively impacts students' success in a course which could be due to the extra effort students put in solving problems (Kuhn, Watson, \& Walters, 2013).

Technology became a must in today's society. Thus, it has become a major part of education as well. Education and learning are emerging because of technology and computers. The use of technology evolved the different ways of learning. Online homework encourages active learning, emphasizes time on task, gives prompt feedback, and accommodates diverse learning (RichardsBabb \& Jackson, 2011). Additionally, online homework benefits students by: providing a correlation between students' online homework scores and exam scores (Malik et al., 2014), and by providing instructors with feedback on concepts that students are exhibiting difficulties in mastering (Flynn, 2012). It is also noteworthy that online homework has other benefits that include promoting student-centered learning and monitoring at risk students in the course (Jones, 2008). Finally, students have positive perceptions about online homework (Smolira, 2008) and online homework has been found to positively impact students' performance (Dillard-Eggers et al., 2008).

Homework plays a significant role in students' learning 
by providing a platform for learning new material, reinforcing old topics, and practicing problems (Hong, Wan, \& Peng, 2009). According to Doorn and co-authors, students "overwhelmingly report that online homework is beneficial in understanding material and preparing for exams" they go on and state that students "felt that it is at least as easy to use as traditional homework, and most recommend it" (Doorn et al., 2010). The work by Richards-Babb and co-workers reinforces this as they state that that $80.2 \%$ of the students in their study group view online homework favorably (Richards-Babb et al., 2011).

Going beyond the student's perspective, online homework has the advantage of saving instructors time by alleviating the pressures of grading homework since it is done by the web platform (Arasasingham et al., 2011). Grading can be quick and easy, with all of the students' work available on one resource. This will allow instructors to focus on improving their lesson plans, evaluation policies, and allocating more time for connecting with their students, which is in favor of the students because it provides them a better understanding of the concepts presented in class. If the teachers are spending more time with their students to explain the content, then the students are more likely master the material.

Online homework has become popular at colleges and universities because it provides individualized feedback to students especially in large classes where it can be considered an arduous task for the instructors (Bonham et al., 2003). Online homework systems allow for ease of distribution of assignments, collecting, and grading student work (Fynewever, 2008). Commercially available online homework systems that are offered through chemistry textbooks' publishers have been found to improve learning (Penn et al., 2000).

Assessment and Learning in Knowledge Spaces (ALEKS) is a responsive and adaptive online homework platform where the homework is tailored based on students' prior knowledge. ALEKS online homework platform is a commercial online learning environment with content related to several subjects including accounting, mathematics and chemistry (Falmagne et al., 2013). ALEKS is a responsive-adaptive online homework system. It is defined as responsive due to its ability to provide feedback and guidance to students working on learning modules, and as adaptive due to its ability to place students into individualized learning spaces based on their performance as the result of continuous monitoring and assessment (Eichler \& Peeples, 2013).

ALEKS online homework platform used Knowledge Space Theory to provide students with individualized learning activities. ALEKS online homework platform continuously monitor and updates individual student's current knowledge-space based on the student's performance on the periodic assessment. ALEKS online homework platform creates individualized learning activities for each student to meet the learning objectives set by the faculty. These learning activities are based on the student's zone of proximal development to ensure meaningful learning (Nilson, 2016).

The way an adaptive online homework system works is that it provides specific feedback to the student which continuously adapts the learning activities and problems to the individual student based on the student's prior and current knowledge of the content (Eichler \& Peeples, 2013). The student's knowledge is continuously monitored which influences the pace and route at which the student progresses through the semester (Eichler \& Peeples, 2013). Adaptive online homework systems have been found to be more effective than traditional online home work in increasing the odds of receiving a higher final grade and improving their study habits, but students has less favorable attitudes towards it (Richards-Babb et al., 2018).

ALEKS online homework platform provides response-specific feedback, which translates to providing specific feedback to individual students based on the error they commit in solving problems in order to address a specific issue while it is continuously adapting the learning activities and assessment (Eichler \& Peeples, 2013). Unlike traditional online homework systems where a set of problems are assigned to all students, ALEKS provides instructor with the opportunity to choose from a list of objectives and then ALEKS creates an individual set of learning activities that are continuously monitored and updated to help each individual student achieve mastery. The learning activities are tailored for an individual student based on student's knowledge and progression thought the content which is significant for meaningful learning (Ausubel et al., 1978). The periodic assessment and continuous monitoring of the student's mastery of the content improve learning and knowledge retention (Krapicke \& Grimaldi, 2012).

Online homework systems give the students instant feedback which has been shown to have a positive impact on students' grades and attitudes towards chemistry (Parker \& Loudon, 2013). Additionally, online homework systems have been found to provide students with meaningful learning gains in general chemistry courses (Libatore, 2011) and positively impacts students' achievements in chemistry (Cole \& Todd, 2003). Online homework systems have the potential to promote a few key principles of good practices in undergraduate education such as active learning, prompt feedback, and time on tasks, which are crucial for courses with high enrollments such 
as general chemistry where students can use all the help they can get (Clickering et al., 1987).

Much of the research on online homework in general chemistry focused on the positive relationship between online homework and improvement on final exams scores (Arasingham et al., 2011), and passing rates and retention (Revel, 2014). One research project data suggests that responsive-adaptive learning systems have a significant positive impact on students' performance in a general chemistry courses (Eichler \& Peeples, 2013).

\section{Guiding Research Questions}

Our research was structured to address the following specific questions:

1. What are the students' levels of perceptions about the usefulness of ALEKS online homework platform?

2. What are the students' levels of perceptions about whether ALEKS online homework platform helps students improve their problem solving skills and study habits?

3. What are the benefits and challenges of ALEKS as students use it as online homework platform?

\section{METHOD}

Our purpose for this research is to investigate the students' perceptions of responsive-adaptive online homework, ALEKS, implemented in the general chemistry courses here at the City College of New York. Students in all sections of general chemistry completed weekly online homework assignments, using the commercially available ALEKS online homework platform. The topics that used ALEKS in this study are the standard topics covered in the two semester sequence of general chemistry courses. Our research design is based on examining students' attitudes and perceptions about ALEKS by using a survey that provided us with data to aid in our investigation. As part of the evaluation and data collection process, the students were given questionnaires to fill out towards the end of the semester. This helped quantify and analyze the students' levels of perceptions of ALEKS on student achievement, attitudes, and learning. The questionnaires contained a Likert-type and open-ended questions that provided us with more information about the implementation of the ALEKS online homework platform into general chemistry. The survey was given to two experts who agree that the questions adequately capture the investigation about ALEKS. As for reliability, the reliability coefficient was found to be 0.81 through the use of test-retest reliability method. Furthermore, we conducted interviews on a subset of the participants to illicit more information and some clarifications, which was valuable in coding the data using rubrics.

The students in this study were enrolled in an urban, commuter school, minority serving institute, and a public college in New York City. The Participants were enrolled in first and second term general chemistry courses during the fall of 2019 and gave their consent to participate in the study which had an Internal Review Board (IRB) approval. Students' participation in the study was voluntary and their identity remained anonymous. Survey was administered and collected from 163 participants ( $N=163)$. After collecting the survey, students' answers were analyzed and categorized using a rubric and illustrated in a form of graphs and pie charts.

For the Likert-type questions, the answers were converted to numerical values and plotted as follows: (1) Strongly Disagree, (2) Disagree, (3) Neutral, (4) Agree, and (5) Strongly Agree. Then the average was calculated for the total students' participants. To gain insights into students' perceptions and attitude about ALEKS online homework platform, students were asked five open-ended short answer questions. For some of the open-ended questions the answers from respondents were coded based a rubric and were converted to numerical values from 1 to $5 \mathrm{sim}$ ilarly to the ones in Likert-type questions. The first and second authors scored the open-ended responses based on the rubric independently. The agreement was found to be $92 \%$ and not one single item had a difference of more than one point on a five-point scale. The two co-authors discussed the discrepancies until consensus was reached. Then the individual values were combined and converted into averages. For some questions that involved lists, categories were created based on respondents answers and converted into percentages and plotted as pie charts. This was also performed by the two coauthors independently and the results were consistent.

\section{RESULTS AND DISCUSSION}

Figure 1 is shows four of the Likert-Type questions and the average answer from respondents. Figure 1 shows that students overall had a positive levels of perceptions of ALEKS. The students agree that ALEKS has helped them understand concepts covered in class, encouraged them to practice outside class, and improved their basic problem solving skills.

Figure 2 is a depiction of another four Likert-Type questions that were on the survey. The data show that ALEKS online homework platform positively impacted students' levels of attitudes about learning and completing assignments. The figure shows that students believe that ALEKS provided them with useful guidance and hints on problem solving, prevented them from falling behind due to the fact that there were weekly assignments to be completed, benefited them by improving their course grade and contributing to their learning, and helped them 




Figure 1. Questions and average answer from respondents for Likert-Type questions

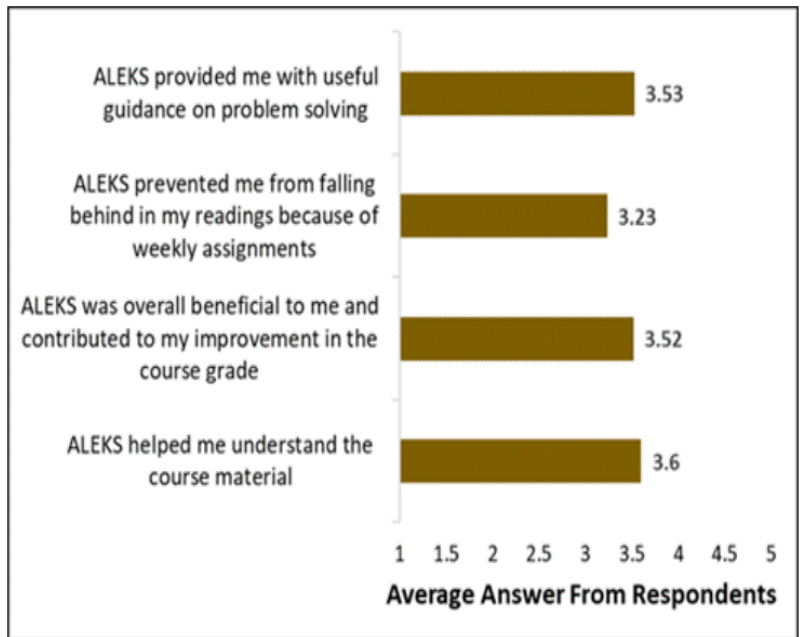

Figure 2. Questions and average answer from respondents for Likert-Type questions

better understand the material covered in the course.

Our data suggests that students underscore the importance of ALEKS online homework. The students' levels of perceptions were overall positive towards ALEKS online homework system where the students perceive ALEKS as helpful in understanding concepts, practicing problem solving outside the classroom, learning how to approach and solve problems, and improving problem solving skills. Furthermore, students' levels of perceptions of ALEKS is that it positively impacted their attitudes about learning and assignments, provided useful feedback and guidance, improved their overall course grades, and prevented them from falling behind. This is aligned with another research study, where it was shown that online homework systems improve student learning of content, experiences with the course's material, and success (Parker \& Loudon, 2013). Generally speaking, research supports the notion that students view online homework in a positive manner (Doorn et al., 2010). Our results are supported by other research in the field where the author correlated online homework assignment completion and performance on final exam and ACS standardized test, however the study did not report on time spent performing the task (Revell, 2014).

Figure 3 shows the time that students spend on a weekly basis on ALEKS as well as other aspects of the course such as reading the textbook, or watching videos related to the topic. Our data show that students spend on average about 190 minutes using ALEKS weekly compared 65 and 45 minutes, watching videos related to the topic and reading the textbook, respectively. The data clearly show that students spend a significant time working and solving problems on ALEKS. This is a positive thing for the students because the more time they spend practicing problems, time on task, the clearer the concept will be to them.

The results of this investigation shows that students spend a significant amount of time solving problems on 


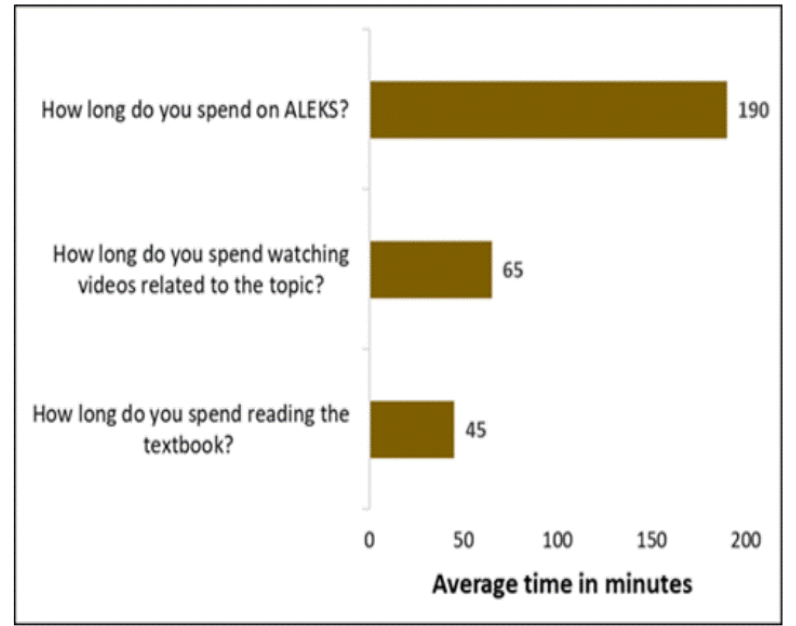

Figure 3. Questions and averages from questions related to amount of time students spend weekly on different parts of the course

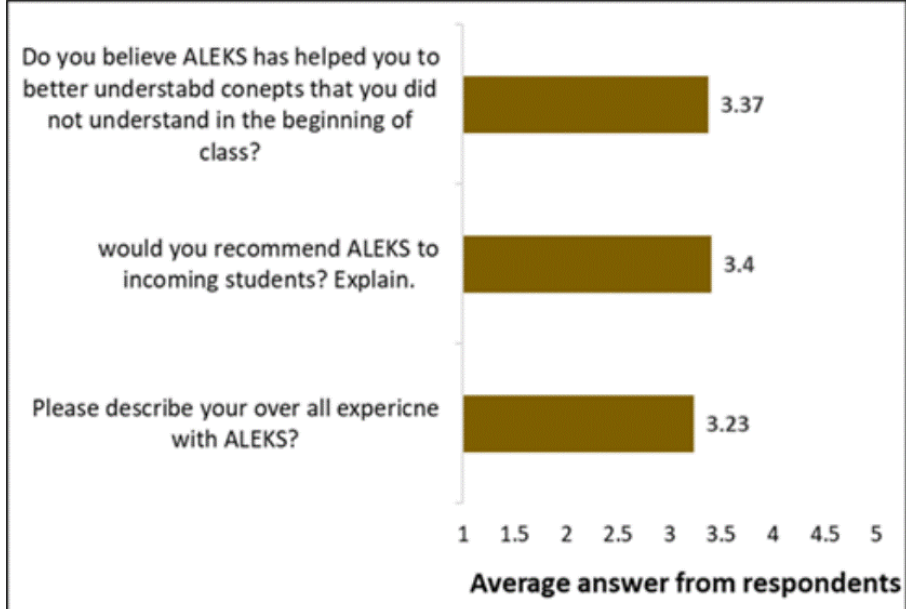

Figure 4. Open ended questions and average answer from respondents based on rubric

ALEKS online homework platform and more so than other aspects of the course. We view this result as a positive one since it shows that ALEKS increases time on task by the students and thus positively impacts learning and study habits. The more time students spend on completing the ALEKS online homework tasks, the more learning they will achieve. This is consistent with educational research that argues that more time students spend on homework, the higher is their achievement in the course (Cooper et al., 2006). Additionally, research into science education underscores the importance of time on tasks and their impact on success in science courses since the more time a student spends on a given task the more actively engaged they are in the process of learning of the material (Slavin, 2003; \& Marks, 2013).

Figure 4 presents the three questions that were asked in the short answer part of the questionnaire. The data show that students' perceptions of ALEKS are neutral about the role ALEKS played to help them better understand the concepts, their recommendation of ALEKS, and their overall experience. We should note that majority of answers were really positive, a score of 5 , or really negative a score of 1 . One explanation is that weaker students spend more time on ALEKS and thus they perceive it negatively. The repeated knowledge checks and continuous monitoring where weaker students have to complete around 20 more problems could be attributed to the frustrations that students face and their negative perceptions of ALEKS. In one study, researchers report that adaptive online homework systems are more effective than traditional online homework system in improving students' study habits and chances of success in the course, however, students has less favorable attitudes towards it (Richards-Babb et al., 2018). Additionally, it was found that higher motivated and better performing students show more satisfaction with online homework (Doorn et al., 2010).

Figure 5 shows the students responses to the features they found most beneficial about ALEKS. Majority of 




Figure 5. A pie chart showing the different aspects of ALEKS that students found most beneficial to their learning

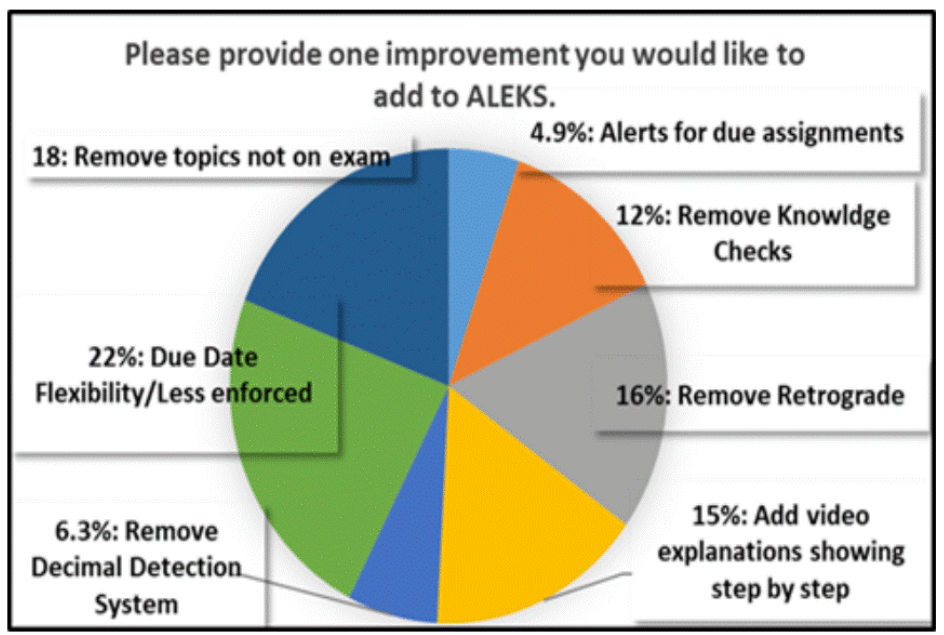

Figure 6. A pie chart depicting things that students would change to improve ALEKS

students, $62 \%$, found the explanation feature, which provides a detailed explanation of the solution to a problem, as the most beneficial to their learning; while pie chart $(11 \%)$, which is a feature that a student can select a pie slice name to see the number of topics, mastered, learned, and remaining for that pie slice, was found as most beneficial aspect of ALEKS. Students reported that knowledge checks (10\%), which measures student's mastery of the topics and operates as a personal tutor, as most beneficial aspect of ALEKS. Students also found that data sheets, $6 \%$, and built in periodic table, $3 \%$, to be beneficial to them. It is noteworthy that $7 \%$ reported that nothing was beneficial about ALEKS. This could be attributed to frustrations with ALEKS system that continuously assess and check prior and current knowledge which could consume a significant amount of the students' time to complete the assignments.

There are several aspects of ALEKS that the students find beneficial to their learning which includes explanation feature, pie chart, and knowledge checks. Although, it seems like some students find no benefit from ALEKS (7\%). One possible explanation could be attributed to the frustrations that weaker students face due to the repeated knowledge checks and continuous monitoring where students have to complete additional 20 to 30 problems each time which could impact their views negatively. Student provided some valuable information on improving ALEKS offerings which includes due date flexibility, explanation videos additions, alerts for deadlines, and retrograde removal.

Figure 6 is a depiction of students' suggestions on improving ALEKS' offerings. The pie chart shows that $22 \%$ of students would recommend flexibility on due dates and $18 \%$ would suggest removal of topics not on exam which could reduce the amount of time spent on ALEKS. Additionally, students recommend removing retrograde $(16 \%)$, adding videos showing step by step explanations (15\%), and removing knowledge checks (12\%), which is a list of questions, typically 20 to 30 , that ALEKS asks students to complete in order to determine their precise 
knowledge state in the course. Students feel that adding alerts for due assignments (4.9\%), as well, as, removing decimal detection system (6.3\%) could be helpful.

It has been suggested the online homework in general chemistry courses provides students with prompt feedback, emphasizes time-on-task, and encourages active learning (Parker \& Loudon, 2013). This is suggested by our research data since online homework ensures that students are actively engaged in knowledge application and problem solving, provide students with prompt feedback on their work, and encourages students to spent a significant amount of time solving problems and achieving mastery of content. Furthermore, research has shown that online homework positively influences students' achievement and learning, improves their attitudes towards the course and increases the increases the amount of time they spend on homework (Allain \& Williams, 2006).

Our data shows that students perceive online homework as positively impacting their learning, increasing their time on tasks, and providing individual feedback and guidance in solving problems. This is consistent with research in chemistry education where it was found that in a large enrollment organic chemistry course students perceived online homework as a useful aspect for learning, revealed positive attitude towards online homework, and suggested that it improved their study habits (RichardsBabb et al., 2015). It is also noteworthy that online homework systems have been found to force students to spend additional time solving individual problems while taking advantages of hints and multiple attempts (Smithrud \& Pinhas, 2015).

\section{CONCLUSION}

ALEKS have provided positive perception/attitudes by students when used in Chemistry courses. Our research shows that implementing ALEKS online homework platform into general chemistry courses positively affected students' levels of perceptions and attitudes of the course material. Furthermore, students' views of ALEKS is that it facilitated their understanding of the concepts covered, improved their problem solving skills, provided them with useful prompt feedback, and improved their chances of successfully completing the course. Furthermore, students' perception of ALEKS is that positively affected their learning experience, understanding, and problem solving skills.

Our most significant finding is that ALEKS implementation increases the amount of time on tasks for students and thus improves their study habits. Students spend a significant amount of time on ALEKS solving problems and going through knowledge checked which directly improve their learning, engagement in the material, and achievement. Students found many aspects of ALEKS online homework to be have benefited their learning which includes explanation features, pie charts, and knowledge checks.

Our data suggests that ALEKS online homework platform contribute to students' active engagement in the course material and establishes a place where students spend a significant amount of time on a weekly basis involved in problem solving and achieving mastery of content. This is crucial to the improvement of meaningful learning. Students perceive ALEKS online homework as positively impacting their learning and understanding, and providing individual feedback and guidance in solving problems.

\section{REFERENCES}

Allain, R., \& Williams, T. (2006). The effectiveness of online homework in an introductory science class. Journal of College Science Teaching, 35(6), 28-35.

Arasingham, R. D., Martorell, I., \& McIntire, T. M. (2011). Online homework and student achievement in a large enrollment introductory science course. Journal of College Science Teaching, 40(6), 70-79.

Ausubel, D. P., Novak, J.D., \& Hanesian, H. (1978). Educational psychology: A cognitive view (second edition). New York: Holt, Rinehart and Winston.

Bonham, S. W., Deardorff, D. L., \& Beichner, R. J. (2003). Comparison of student performance using web and paperbased homework in college-level physics. Journal of Research in Science Teaching, 40(10), 1050-1071. https://doi. org/10.1002/tea.10120

Charlesworth P., \& Vician, C. (2003). Leveraging technology for chemical sciences education: an early assessment of WebCT usage in first-year chemistry courses. Journal of Chemical Education, 80, 1333-1337.

Chickering, A., Gamson, Z., \& Poulsen, S. (1987). Seven principles for good practice in undergraduate education. American Association for Higher Education Bulletin, 17, 140-141.

Cole, R., \& Todd, J. (2003). Effects of web-based multimedia homework with immediate rich feedback on student learning in general chemistry. Journal of Chemical Education, 80(11), 1338.

Cooper, H.M. (2001). The battle over homework: Common ground for administrators, teachers, and parents, 2nd ed.; Corwin Press: Thousand Oaks, CA.

Cooper, H., Robinson, J. C., \& Patall, E. A. (2006). Does homework improve academic achievement? A synthesis of research. 1987-2003. Review of Educational Research, 76(1), 1-62. https://doi.org/10.3102/00346543076001001

Dillard-Eggers, J., T. Wooten, Childs, B., \& Coker, J. (2008). Evidence on the effectiveness of on-line homework. College Teaching Methods and Styles Journal, 4(5), 9-15.

Doorn, D., Janssen, S., \& O’brien, M. (2010). Student attitudes and approaches to online homework. International Journal for the Scholarship of Teaching and Learning, 4(1), 1-20. https://doi.org/10.20429/ijsotl.2010.040105 
Eichler, J. F., \& Peeples, J. (2013). Online homework put to the test: A report on the impact of two online learning systems on student performance in general chemistry. Journal of Chemical Education. 90, 1137-1143. https://doi.org/10.1021/ ed3006264

Falmagne, J.C., Albert, D., Doble, C., Eppstein, D., \& Hu, X., (Eds.) (2013). Knowledge spaces. Berlin, Germany: Springer.

Flynn, A. B. (2012). Development of online, postclass question method and its integration with teaching strategies. Journal of Chemical Education, 89, 456-464.

Fynewever, H. (2008). A comparison of the effectiveness of webbased and paper-based homework for general chemistry. Chemical Educator, 13, 264-269.

Hong, E., Wan, M., \& Peng, Y. (2009). Discrepancies between students and teachers perceptions of homework. Journal of Advanced Academics, 22(2), 280-308. https://doi. org/10.1177/1932202X1102200205

Jones, C. G. (2008). Student perception of the impact of webbased homework on course interaction and learning in introductory accounting. Issues in Information Systems, 9, 223-232.

Kuhn, S. W., Watson, S. W., \& Walters, T. J. (2013). Online homework and correlated success in university mathematics courses. In L. Kyei-Blankson \& E. Ntuli (Eds.), Practical Applications and Experiences in K-20 Blended Learning Environments (pp. 307-329). Hershey, PA: IGI Global.

Libatore, M. W. (2011). Improved student achievement using personalized online homework for a course in material and energy balances. Chemical Engineering Education, 45(3), 184-190.

Malik, K., Martinez, N., Romero, J., Schubel, S., \& Janowicz, P. A. (2014). Mixed-methods study of online and written organic chemistry homework. Journal of Chemical Education, 91, 1804-1809.

Marks, H. (2013). Student engagement in instructional activity: Patterns in elementary, middle and high school years. American Educational Research Journal, 37, 153-184. https:// doi.org/10.3102/00028312037001153

McGraw Hill Education ALEKS Home Page. https://www.aleks. com/ (accessed May 2020).

Nilson, L. B. (2016). Teaching at Its Best, 4th ed.; Jossey-Bass: San Francisco, CA.

Parker, L. L., \& Loudon, G. M. (2013). Case study using online homework in undergraduate organic chemistry: Results and student attitudes. Journal of Chemical Education, 90, 37-44. https://doi.org/10.1021/ed300270t

Penn, J., Nedeff, V. M., \& Gozdzik. G. (2000). Organic chemistry and the internet: A web-based approach to homework and testing using the WE-LEARN system. Journal of Chemical Education, 77(2), 227-231. https://doi.org/10.1021/ ed077p227

Revell, K. D. (2014). A comparison of the usage of tablet PC, lecture capture, and online homework in an introductory chemistry course. Journal of Chemical Education, 91(1), 4851. https://doi.org/10.1021/ed400372x

Richards-Babb, M., Drelick, J., Henry, Z., \& Robertson-Honecker, J. (2011). Online homework, help or hindrance? What students think and how they perform. Journal of College Science Teaching, 40(4), 81-93. https://www.learntechlib. org/p/54012/
Richards-Babb, M., \& Jackson, J. K. (2011). Gendered responses to online homework use in general chemistry. Chemistry Education Research and Practice, 12, 409-419.

Richards-Babb, M., Curtis, R., Georgieva, Z., \& Penn, J. H. (2015). Student perceptions of online homework use for formative assessment of learning in organic chemistry. Journal of Chemical Education, 92, 1813-1819. DOI:10.1021/ acs.jchemed.5b00294

Richards-Babb, M. Reagan C. R., Ratcliff, B., Roy, A., \& Mikalik, T. (2018). General chemistry student attitudes and success with use of online homework: Traditional-responsive versus adaptive-responsive. Journal of Chemical Education, 95, 691-699. https://doi.org/10.1021/acs.jchemed.7b00829

Slavin, R. (2003). Educational psychology: Theory and practice; Pearson Education: Boston.

Smithrud, D. B., \& Pinhas, A. R. (2015). Pencil-paper learning should be combined with online homework software. Journal of Chemical Education, 92, 1965-1970. https://doi. org/10.1021/ed500594g

Smolira, J. C. (2008). Student perceptions of online homework in introductory finance courses. Journal of Education for Business, 83, 90-94. 